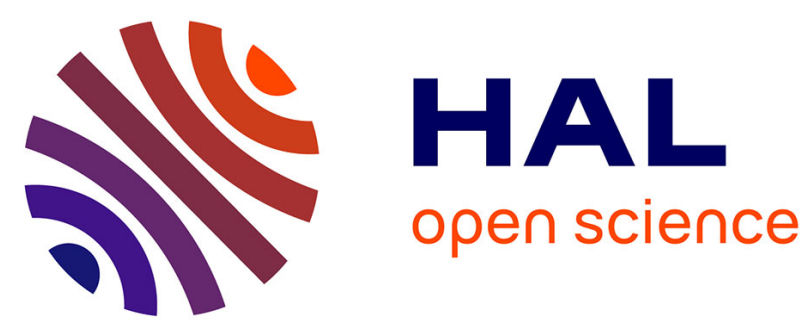

\title{
Excito-repellent activity of $\beta$-caryophyllene oxide against Aedes aegypti and Anopheles minimus
}

\author{
Jirod Nararak, Sunaiyana Sathantriphop, Monthathip Kongmee, Valerie \\ Mahiou-Leddet, Evelyne Ollivier, Sylvie Manguin, Theeraphap \\ Chareonviriyaphap
}

\section{To cite this version:}

Jirod Nararak, Sunaiyana Sathantriphop, Monthathip Kongmee, Valerie Mahiou-Leddet, Evelyne Ollivier, et al.. Excito-repellent activity of $\beta$-caryophyllene oxide against Aedes aegypti and Anopheles minimus. Acta Tropica, 2019, 197, pp.1-8/105030. 10.1016/j.actatropica.2019.05.021 . hal-02415271

\section{HAL Id: hal-02415271 \\ https://hal-amu.archives-ouvertes.fr/hal-02415271}

Submitted on 17 Dec 2019

HAL is a multi-disciplinary open access archive for the deposit and dissemination of scientific research documents, whether they are published or not. The documents may come from teaching and research institutions in France or abroad, or from public or private research centers.
L'archive ouverte pluridisciplinaire HAL, est destinée au dépôt et à la diffusion de documents scientifiques de niveau recherche, publiés ou non, émanant des établissements d'enseignement et de recherche français ou étrangers, des laboratoires publics ou privés. 
Acta Tropica

Excito-repellency and biological safety of $\beta$-caryophyllene oxide against Aedes

albopictus and Anopheles dirus (Diptera: Culicidae)

Jirod Nararak ${ }^{\mathrm{a}, \mathrm{b}}$, Carole Di Giorgio ${ }^{\mathrm{c}}$, Chutipong Sukkanon ${ }^{\mathrm{a}}$, Valerie Mahiou-Leddet ${ }^{\mathrm{c}}$, Evelyne

Ollivier $^{\mathrm{c}}$, Sylvie Manguin ${ }^{\mathrm{b}}$ and Theeraphap Chareonviriyaphap ${ }^{\mathrm{a}}$

${ }^{\text {a }}$ Department of Entomology, Faculty of Agriculture, Kasetsart University, Bangkok 10900, Thailand

${ }^{\mathrm{b}}$ HydroSciences Montpellier (HSM), Institut de Recherche pour le Développement (IRD), CNRS, Université Montpellier, Montpellier, France

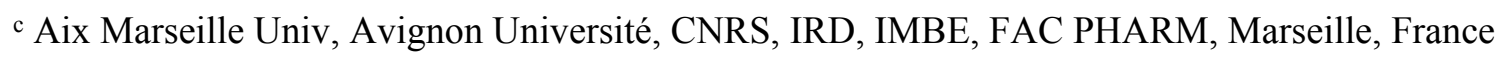

\author{
E-mail addresses: JN: (rgt532@gmail.com) \\ CG: (carole.di-giorgio@univ-amu.fr) \\ CS: (c.sukkanon@gmail.com) \\ VM: (valerie.mahiou@univ-amu.fr) \\ EO: (evelyne.ollivier@univ-amu.fr) \\ SM: (sylvie.manguin@ird.fr)
}

TC: (faasthc@ku.ac.th)

*Corresponding author: Prof. Theeraphap Chareonviriyaphap, Ph.D.

Department of Entomology, Faculty of Agriculture,

Kasetsart University, Bangkok, Thailand, 10900.

E-mail: faasthc@ku.ac.th 


\section{Highlights}

- $\quad \beta$-caryophyllene oxide had stronger repellent and irritant effect than DEET

- Ae. albopictus was more sensitive to $\beta$-caryophyllene oxide than An. dirus while, knockdown responses (37\%) were observed in An. dirus exposed to $1 \% \beta$-caryophyllene oxide in the contact trial.

- $\quad \beta$-caryophyllene oxide did not show any phototoxic activity.

- None of the tested $\beta$-caryophyllene oxide induced a significant increase of micronucleated cells with or without metabolic activation.

- $\quad \beta$-Caryophyllene oxide could be considered as a safe repellent, effective against mosquitoes. 


\begin{abstract}
The activity of $\beta$-caryophyllene oxide as either a contact or non-contact repellent was evaluated against two laboratory strains (Aedes albopictus and Anopheles dirus) using an excitorepellency test system. $N, N$-Diethyl-3-methylbenzamide (DEET) was used as a standard reference baseline for comparative purposes. $\beta$-Caryophyllene oxide and DEET were tested at concentrations of $0.1,0.25,0.5$ and $1.0 \%(\mathrm{v} / \mathrm{v})$. In addition, the phototoxic and genotoxic effects of $\beta$-caryophyllene oxide were investigated on Balb/c 3T3 mouse fibroblasts (3T3-L1) and Chinese hamster ovary cell line (CHO-K1). The results demonstrated that the higher concentrations of test compounds $(0.5$ and $1.0 \%)$ produced greater behavioral responses. Ae. albopictus was more sensitive to $\beta$-caryophyllene oxide than An. dirus. Moderate avoidance response rates (25-56\% escape) of Ae. albopictus at $0.5 \%$ and $1.0 \% \beta$-caryophyllene oxide were observed in contact and non-contact trials compared with low response rates from An. dirus (26$31 \%$ escape). DEET at $\leq 1 \%$ displayed lower irritancy and repellency $(1-38 \%)$ than $\beta$ caryophyllene oxide when tested against the two mosquito species. Knockdown responses (37\%) were only observed in An. dirus exposed to $1 \% \beta$-caryophyllene oxide in the contact trial. $\beta$ Caryophyllene oxide did not show any phototoxic potential $(\mathrm{PIF}=0.38)$ nor was there any significant genotoxic response as indicated by no increase in micro-nucleated cells with or without metabolic activation. $\beta$-Caryophyllene oxide could be considered as a safe repellent, effective against mosquitoes.
\end{abstract}

Keywords: Excito-repellency test system, $\beta$-Caryophyllene oxide, Phototoxic, Genotoxic, Mosquitoes 
3 Mosquitoes serve as vectors of pathogens for devastating human scourge, including malaria,

4 filariasis, yellow fever, dengue, West Nile virus and chikungunya (Benelli and Mehlhorn, 5 2018). Malaria and dengue are the two most common mosquito-borne diseases that cause high 6 morbidity and mortality (Wiwanitkit, 2011). Millions of humans in undeveloped and 7 developing countries are now at risk from these diseases. To a lower extent, developed 8 countries are too at risk of dengue outbreaks due to the invasion of Aedes albopictus into 9 temperate regions and population movement from dengue-endemic areas. In 2017, an estimated 219 million cases of malaria occurred worldwide, with an estimated 435,000 deaths

11 from malaria globally (WHO, 2018). Anopheles dirus is the one of the most important malaria vector in Southeast Asia (Tainchum et al., 2015). This species inhabits forest and forest fringes and exhibits mostly exophagic behavior (Baimai et al., 1984; 2019; Tananchai et al., 2012). In contrast, dengue and chikungunya are arboviral infections transmitted by two species of Aedes mosquitoes-Ae. aegypti L. and Ae. albopictus (Skuse). The latter, known as the Asian tiger mosquito, is native from Southeast Asian countries (Smith, 1956). The distribution of Ae. albopictus has been extended recently by invasion into more northerly latitudes as well as into higher altitudes such as the United States of America and Southern Europe (Chouin-Carneiro et al., 2016; Fidyt et al., 2016).

Personal protection using insect repellents is considered as one of the most efficient measures which has been widely used to reduce the outdoor transmission of mosquito-borne diseases (Debboun and Strickman, 2013). Commercial mosquito repellents containing $N, N$ Diethyl-3-methylbenzamide (DEET) have been used by people worldwide. Research has suggested that DEET is not safe when applied to children's skin or if improperly used 
(Briassoulis et al., 2001). Several side effects have been reported from DEET including rash,

skin irritation and eye irritation (Amichai et al., 1994; Patel et al., 2012).

In addition, mosquitoes have developed resistance to all main groups of insecticides (organochlorines, organophosphates, carbamates). For example, the commonly used pyrethroids are applied to control malaria mosquitoes but have become increasingly less effective due to the development of physiological resistance in mosquito populations (Chareonviriyaphap et al., 2000; 2013). Consequently, alternative plant-based repellents have been used to protect people, particularly children, during outdoor activities. In addition, such alternative repellents cause no harm to various nontarget organisms (with additional benefits as a potential source of bioactive chemicals, fragrances and flavoring agents) and are recommended as an alternative source of materials for insect control (Isman, 2002; Yang et al., 2005).

$\beta$-Caryophyllene oxide is generally found in essential oils of various plant species such as Artemisia anomala S. Moore, Salvia miltiorrhiza Bunge, Chloroxylon swietenia DC., Psidium guajava L., Origanum vulgare L., Cinnamomum spp., Syzygium aromaticum (L.) Merr. \& L.M. Perry, Piper nigrum L. and Serjania yucatanensis Standl. (Garneau et al., 2013; Gertsch et al., 2008; Jun et al., 2011; Liang et al., 2009; Polanco-Hernández et al., 2012; Shell, 1997; Telang et al., 2003; Zhao et al., 2013) Furthermore, $\beta$-caryophyllene oxide has been reported to repel mosquitoes. Suleiman et al. (2014) reported that leaves of Artabotrys hexapetalus (L. f.) Bhandari contained large amounts of $\beta$-caryophyllene oxide with high mosquito repellent activity against Anopheles gambiae s.s. in Africa. A more recent study reported that Aedes aegypti and Anopheles minimus exhibited high avoidance response rates at $0.5 \%$ and $1 \%$ concentrations of $\beta$-caryophyllene oxide compared to DEET (Nararak et al., 2019), showing the high repellent potential of this molecule. 
In recent years, the food and cosmetic industries and both national and international

health and food safety authorities have extensively debated the safety of novel plants and plantderived ingredients for their use in foods. These discussions consistently produced a consensus that adequate specifications of plant identity and composition are key issues in the safety assessment of plant-derived ingredients (Antignac et al., 2011). Although $\beta$-caryophyllene oxide is beneficial as a mosquito repellent, this compound may produce toxic and adverse effects on humans or animals or both. Consequently, potential cytotoxic effects of hazardous substances must be assessed prior to product development. Little scientific data is available on the possible adverse effects or the biological safety of $\beta$-caryophyllene oxide in experimental administration to animals. What has been reported is that based on a biomembrane model, $\beta$ caryophyllene oxide could pass through the cell membrane without inducing genotoxic effects at the gene or chromosomal level (Di Sotto et al., 2013).

In the current study, following the repellent study already done on Aedes aegypti and An. minimus (Nararak et al., 2019), we investigated the active excito-repellent properties of $\beta$ caryophyllene oxide against Ae. albopictus and An. dirus, using an excito-repellency (ER) test system. The excito repellency (ER) test system is the gold standard to quantitatively determine the two distinct forms of behavioral responses in mosquito population in response to test chemicals (Sathantriphop et al., 2006). A test chamber system and protocol that can easily differentiate these two types of behavioral responses has been described (Chareonviriyaphap et al., 1997; Roberts et al., 1997). Moreover, in the current study, we evaluated the safety of $\beta$-caryophyllene oxide using an in vitro photoxicity test and an in vitro micronucleus assay. 


\subsection{Mosquitoes used}

Samples of Aedes albopictus were originally captured in 1996 in Chanthaburi province, eastern Thailand by staff from the Ministry of Public Health, Thailand. Representatives of this population have been maintained in the entomological laboratory at Kasetsart University for since 2013 and females only were used in the current study. Samples of Anopheles dirus were based on individuals originally collected in 1981 in Khao Mai Kaeo sub-district, Bang Lamung district, Chonburi province, eastern Thailand. These two mosquito species were reared in separate insectaries of the Department of Entomology, Faculty of Agriculture, Kasetsart University, Bangkok, Thailand. All larvae and adults were held under laboratory-controlled conditions of $25 \pm 5^{\circ} \mathrm{C}$ and $80 \pm 10 \%$ relative humidity with a 12:12 (L:D) photoperiod. Larvae were fed with fish food twice daily. Adults were reared in a screened cage and provided with $10 \%$ sugar solution as food. Three-to-five day-old female mosquitoes were starved for $24 \mathrm{~h}$ before testing.

\subsection{Test compounds}

DEET ( $N, N$-Diethyl-3-methylbenzamide) with 97\% purity obtained from the SigmaAldrich Company Ltd. (Lot No: MKBH0428V) was used as the gold standard insect repellent. $\beta$-Caryophyllene oxide was purchased from the Acros Organics Company Ltd. (95\% purity, Lot No: A0356135).

\subsection{Filter paper treatment}

$\beta$-Caryophyllene oxide and DEET were diluted with absolute ethanol to provide respective concentrations of $0.1,0.25,0.5$ and $1.0 \%(\mathrm{v} / \mathrm{v})$. The $2.8 \mathrm{~mL}$ test solution was spread evenly over the fine surface of filter paper $(14.7 \times 17.5 \mathrm{~cm})$ using a $5 \mathrm{~mL}$ serological pipette and pipette controller. Similar treated papers for four replicates were prepared for each concentration and the control papers were treated with absolute ethanol only. All treated papers 
were air-dried in a horizontal position at room temperature for $1 \mathrm{~h}$ prior to starting the test. All solutions and treated papers were freshly prepared on the day required.

\subsection{Excito-repellency test system}

Experiments were conducted to compare the behavioral responses of mosquitoes using an excito-repellency test system described by (Chareonviriyaphap et al., 2002). The test system consisted of two pairs each for contact and noncontact exposure chambers. For a pair of contact chambers, the treated papers were placed on the inside of a screened inner chamber so that female mosquitoes could rest directly on the treated papers. Alternatively, a pair of noncontact trials had treated papers outside the screened inner chamber, which prevented the female mosquitoes from resting directly on the treated papers. Fifteen healthy, unfed female mosquitoes were introduced into four chambers simultaneously using a mouth aspirator and allowed 3 min to adjust to the chambers. Subsequently, the escape funnels were opened to begin the observation period. The number of mosquitoes escaping from the chamber into the receiving cage was recorded at $1 \mathrm{~min}$ intervals for a total of $30 \mathrm{~min}$. After the $30 \mathrm{~min}$ exposure period, the numbers of knockdown and dead mosquitoes were recorded separately. All mosquitoes that either escaped to the receiving box or remained inside the chamber were kept in clean plastic cups and provided with cotton pads soaked with $10 \%$ sugar solution for $24 \mathrm{~h}$. The numbers of both knockdown and mortality were respectively recorded after $30 \mathrm{~min}$ exposure and after $24 \mathrm{~h}$.

The mean percentage of escaped mosquitoes was calculated per test chamber. Abbott's formula was applied to adjust escape responses based on paired control escape responses (Abbott, 1987). A log-rank test was used to analyze paired comparisons of the escape patterns based on the compound, species and concentrations (Mantel and Haenszel, 1959). Statistical significance was accepted for all tests at $P<0.05$. 
oxide, the safety evaluation showed no prohibited or restricted components. For safety reasons, the in vitro $3 \mathrm{~T} 3 \mathrm{NRU}$ phototoxicity test $\left(\mathrm{OECD} \mathrm{N}^{\circ} 432\right)$ was first conducted to identify the toxicity of the test substance induced by the excited chemicals after exposure to light. The 3T3 NRU phototoxicity test is based on the comparison of a chemical when tested in the presence and in the absence of exposure to a non-cytotoxic dose of simulated solar light. Cytotoxicity is expressed as a concentration-dependent reduction of the uptake of the vital dye Neutral Red when measured $24 \mathrm{~h}$ after chemical treatment and irradiation.

Balb/c 3 T3 mouse fibroblasts (3T3-L1) (ATCC, USA, ATCC® CL-173 ${ }^{\mathrm{TM}}, \mathrm{N}^{\circ}$ P6110401, Lot. 09I006), low passage number $(<50)$, maintained into DMEM (Dulbecco's Minimum Essential Medium, PAN BIOTECH. lot 1874561) supplemented with penicillin 100 IU/mL, streptomycin $100 \mu \mathrm{g} / \mathrm{mL}$ (PAN BIOTECH, Lot 945514) and 10\% inactivated calf serum (PAN BIOTECH, Lot P56314), were seeded into two 96-well tissue culture plates (0.1 $\mathrm{mL}$ per well) at concentration of $1 \times 10^{5}$ cells $/ \mathrm{mL}$, and incubated at $37^{\circ} \mathrm{C}(5 \% \mathrm{CO} 2)$ for $24 \mathrm{~h}$ until semi-confluent. At the end of the incubation period, the culture medium was decanted and replaced by $100 \mu \mathrm{L}$ of Hank's balanced salt solution (HBSS) containing the appropriate concentrations of the test substance (eight different concentrations). Subsequently, cells were incubated at $37^{\circ} \mathrm{C}\left(5 \% \mathrm{CO}_{2}\right)$ in the dark for $60 \mathrm{~min}$. From the two plates prepared for each series of test substance concentrations and the controls, one was randomly selected for the

140 determination of cytotoxicity without irradiation (-Irr), and the other for the determination of photo-cytotoxicity with irradiation (+Irr). The irradiation procedure was performed using a solar simulator Suntest CPS+ apparatus (Atlas Material Testing Technology BV, Moussy le

143 Neuf, France) equipped with a xenon arc lamp $(1,100 \mathrm{~W})$, a special glass filter restricting 144 transmission of light below $290 \mathrm{~nm}$ and a near IR-blocking filter. The irradiance was fixed at 
$145750 \mathrm{~W} / \mathrm{m}^{2}$ throughout the experiments and the combined light dose was $5 \mathrm{~J} / \mathrm{cm}^{2} / \mathrm{min}$ based on

146 UVA irradiation $\left(0.41 \mathrm{~J} / \mathrm{cm}^{2}\right)$ or visible irradiation $\left(4.06 \mathrm{~J} / \mathrm{cm}^{2}\right)$. The test solution was removed,

147 cells were rinsed twice with $150 \mu \mathrm{L}$ HBSS and incubated for $18-22 \mathrm{~h}$ in $0.1 \mathrm{~mL}$ of culture 148 medium at $37^{\circ} \mathrm{C}\left(5 \% \mathrm{CO}_{2}\right)$. Cells were washed, placed into Neutral Red medium $(50 \mu \mathrm{g} / \mathrm{mL}$

149 Neutral Red in complete medium) and incubated for $3 \mathrm{~h}$ at $37^{\circ} \mathrm{C}, 5 \% \mathrm{CO}$. Then the medium 150 was removed and cells were washed three times with $0.2 \mathrm{~mL}$ of HBSS to remove any excess 151 dye. The Neutral Red medium was removed and destaining solution (50\% ethanol, $1 \%$ acetic acid, $49 \%$ distilled water; $50 \mu \mathrm{L}$ per well) was added into each well. Then, the plates were shaken for 15-20 min at room temperature in the dark. All the test samples and controls were run in triplicate in three independent experiments. A positive control (chlorpromazine 155 (SIGMA), final concentrations $1-100 \mu \mathrm{g} / \mathrm{mL}$ without irradiation and 0.01 to $1 \mu \mathrm{g} / \mathrm{mL}$ with irradiation) and a negative control (HBSS) were included in each set of experiments. Cell viability (increase Neutral Red uptake) was measured using a fluorescence-luminescence reader (Infinite M200 Pro, TECAN). The optical density (OD) of each well was read at 540 nm. The results obtained for wells treated with the test material were compared to those of untreated control wells (HBSS, 100\% viability) and converted to percentage values. The concentrations were calculated for the test material causing a 50\% release of the preloaded Neutral Red without irradiation $\left(\mathrm{IC}_{50}-\mathrm{Irr}\right)$ and with irradiation $\left(\mathrm{IC}_{50}+\mathrm{Irr}\right)$ compared to the control culture using the Phototox Version 2.0 software (Federal Institute for Risk Assessment,

164 zebet@bfr.bund.d). The mean OD value of blank wells (containing only Neutral Red desorbed solution) was subtracted from the mean OD value of three treated wells (dilutions of the test material, positive control or HBSS). The percentages of cell viability were calculated as: 


$$
\mathrm{PIF}=\frac{\operatorname{IC50}(-\mathrm{Irr})}{\mathrm{IC} 50(+\mathrm{Irr})}
$$

Based on validation studies, a test substance with a $\mathrm{PIF}<2$ predicts no phototoxicity, a PIF between 2 and 5 predicts a probable phototoxicity and a PIF $>5$ predicts phototoxicity. Then, the in vitro micronucleus assay (MNvit) was used to detect the long-term toxicity

177 of the chemical. Micronucleus assay is a mutagenicity assay which is based on the detection of micronuclei (MNC) in the cytoplasm of interphase cells and allows the detection of the cytogenetic activity of clastogenic or aneugenic compounds or both in cell culture (Johnson et al., 2010). The micronucleus assay was performed on a Chinese hamster ovary cell line (CHO$\mathrm{K} 1$; ATCC, USA) maintained in McCoy's 5A medium supplemented with $1 \mathrm{mM}$ glutamine, $100 \mathrm{unit} / \mathrm{mL}$ and $10 \mu \mathrm{g} / \mathrm{mL}$ of a mixture of penicillin and streptomycin, respectively and $10 \%$ of inactivated calf serum. The CHO-K1 cells were transferred into Labteck wells at a concentration of 100,000 cells $/ \mathrm{mL}$, and incubated for $24 \mathrm{~h}$ at $37^{\circ} \mathrm{C}$ in $\mathrm{CO}_{2}(5 \%)$. When the test was performed without metabolic activation, the test substance was added into cell cultures at the concentrations previously defined. A negative control containing culture medium, a solvent control containing $1 \%$ DMSO and a positive control containing $0.6 \mu \mathrm{g} / \mathrm{mL}$ of mitomycin $\mathrm{C}$ were added.

When the assay was performed in the presence of metabolic activation, S9 mix metabolizing mixture was added to cell cultures at a concentration of $10 \%$. The metabolic activation system (S9) was a 9,000 g centrifuged supernatant of a liver homogenate (S9) and was prepared from male Sprague-Dawley rats treated with a single injection of Aroclor 1254 (500 $\mathrm{mg} / \mathrm{kg}$ body weight). The protein concentration in the $\mathrm{S} 9$ homogenate was $26 \mathrm{mg} / \mathrm{mL}$ as

194 determined by the method of Lowry. S9 mix contained 10\% S9, 5 mM G6P, 4 mM NADP, 33 
15

$\mathrm{mM} \mathrm{KCl}$, and $8 \mathrm{mM} \mathrm{MgCl} 2$ diluted in saline phosphate buffer. Then, the test substance was added to the cell cultures at the concentrations previously defined. A negative control containing culture medium, a solvent control containing 1\% DMSO and a positive control containing $5 \mu \mathrm{g} / \mathrm{mL}$ of benzo[a]pyrene were added.

After $3 \mathrm{~h}$ of incubation at $37{ }^{\circ} \mathrm{C}$ in $\mathrm{CO}_{2}(5 \%)$, the culture medium was removed, the cells were rinsed with phosphate buffered saline (PBS), and then returned to culture in McCoy's 5A medium containing $3 \mu \mathrm{g} / \mathrm{mL}$ of cytochalasin B. After incubation for $21 \mathrm{~h}$ at $37^{\circ} \mathrm{C}$, the cells were rinsed with PBS, fixed with methanol and stained with $10 \%$ Giemsa for $20 \mathrm{~min}$.

The results were analyzed under a microscope at $\times 1,000$ magnification. The antiproliferative activity of test substances was estimated by counting the number of binucleated cells relative to the number of mononucleated cells for 500 cells for each dose (250 cells counted per well). The cytokinesis blocked proliferative index (CBPI) was calculated using the following formula:

$$
\mathrm{CBPI}=\frac{2 \times(\mathrm{BI}+\mathrm{MONO})}{500}
$$

where, $\mathrm{BI}$ is the number of binucleated cells and MONO is the number of mononucleated cells The cytostasis index $(\mathrm{CI} \%)$ is the percentage of cell replication inhibition and was calculated using the following formula:

$$
\mathrm{CI} \%=100-\left(\frac{100 \times(\text { CBPItest material }-1)}{\text { CBPIsolvent control }-1}\right)
$$

After this step, only the doses inducing a decrease of less than $55 \pm 5 \%$ of $\mathrm{CI} \%$ compared to the negative control were considered for counting micronuclei. The rates of micronuclei 
219 were evaluated for the presence of independent nuclear core entities in 1,000 binucleated cells

220 per well, which corresponded to 2,000 cells examined by test substance dose. Micronuclei

221 were identified as small nuclei well-differentiated from the cell nucleus, stained in the same

222 manner and having a diameter less than one-third of that of the cell nucleus. The micronuclei

223 rates obtained for different doses of test substances were compared to the negative control using

224 a $\chi 2$ test. The assay was considered positive if a dose-response relationship was obtained

225 between the rate of micronuclei and the doses tested, where at least one of these doses induced

226 a statistically significant increase $(P<0.05)$ in the number of micronucleated cells compared

227 to the negative control. 
$1.0 \% \mathrm{v} / \mathrm{v}$ of DEET and $\beta$-caryophyllene oxide were evaluated for contact irritancy and noncontact repellency responses using an excito-repellency system. DEET was used as a standard repellent for comparison purposes. The results showed that Ae. albopictus (3.51-56.36\%) had a much higher escape response to $\beta$-caryophyllene oxide than An. dirus $(0-32.73 \%)$ in both the contact and non-contact trials (Table 1). A higher escape response percentage was seen from the contact chamber than from the noncontact chamber and control, regardless of test compounds and concentrations.

The escape responses of Ae. albopictus to $\beta$-caryophyllene oxide were characterized in contact and noncontact exposure chambers by comparison to DEET (Table 1). $\beta$ Caryophyllene oxide at 0.5 and $1.0 \%$ elicited stronger escape responses than DEET in the contact and noncontact treatments. No knockdown and mortality were observed from treatments and control chambers at all concentrations. The greater escape response percentages of Ae. albopictus were observed at 0.5 and $1.0 \%$ in the contact trial with $\beta$-caryophyllene oxide

243 (46.43 and 56.36\%, respectively) and DEET (38.98 and 38.18\% respectively). For An. dirus, the stronger escape responses were found at 0.5 and $1.0 \%$, in both contact $(26.32$ and $32.73 \%$ respectively) and non-contact trial (31.03 and 31.67\%, respectively) as shown in Table 1. A knockdown response (37\%) was observed in An. dirus exposed to $1 \% \beta$-caryophyllene oxide 247 in the contact trial.

The escape patterns from the chambers using survival curves at 1 min intervals in the contact and noncontact designs with paired controls under different concentrations of $\beta$ caryophyllene oxide and DEET against Ae. albopictus and An. dirus are shown in Figures 1-4. The rates represent probabilities for escaping from a chamber with a particular compound and concentration. Overall, $\beta$-caryophyllene oxide exhibited a strong escape response in both 
contact and noncontact trials at all concentrations. Delayed escape responses were observed

254 for 0.1 and $0.25 \%$ with all compounds in the contact and noncontact trials (Figures $1-2)$. With

255 Ae. albopictus, strong contact escape patterns were evident for 0.5 and $1.0 \% \beta$-caryophyllene oxide (Figures 3-4).

The multiple log-rank comparisons of Ae. albopictus and An. dirus in the paired contact and noncontact treatment trials for $\beta$-caryophyllene oxide and DEET are shown in Table 2. Interestingly, there were no significant differences in escape patterns for contact versus noncontact trials, except for $0.5 \%$ and $1.0 \%$ with Ae. albopictus (Table 2).

The statistical comparison of the escape responses for mosquitoes exposed to $\beta$ caryophyllene oxide compared to DEET, at different concentrations, are presented in Table 3. In both the contact and noncontact trials using Ae. albopictus, the escape responses were significantly higher with $\beta$-caryophyllene oxide than DEET at $1.0 \%$ concentration. For $A n$. dirus, the escape responses were significantly more important with $\beta$-caryophyllene oxide than DEET in the noncontact trials at 0.5 and $1 \%$. The statistical comparisons between the two species exposed to $\beta$-caryophyllene oxide and DEET in either the contact or noncontact trials are shown in Table 4. For $\beta$-caryophyllene oxide, Ae. albopictus showed significantly higher escape responses compared to An. dirus in the contact trials at $0.5 \%$ and $1.0 \%(P=0.0184$ and 0.0024 , respectively), while significance differences in the escape responses were found at $0.5 \%$ in both contact and noncontact trials using DEET.

The cytotoxic potential of $\beta$-caryophyllene oxide was evaluated in murine fibroblasts (3 T3) incubated with the compound $(0.1-10 \mathrm{mg} / \mathrm{mL})$. The compound exhibited negligible cytotoxicity $\left(\mathrm{IC}_{50}=13.23 \pm 1.37 \mu \mathrm{g} / \mathrm{mL}\right)$ as shown in Table 5. PIF values were used to classify the phototoxicity potential (Table 5$)$. The phototoxicity assay considered dark $\left(\mathrm{IC}_{50}=\right.$ 13.23 $\pm 1.37 \mu \mathrm{g} / \mathrm{mL})$ and irradiated $\left(\mathrm{IC}_{50}=34.79 \pm 5.49 \mu \mathrm{g} / \mathrm{mL}\right)$ conditions. According to the 
analyses, $\beta$-caryophyllene oxide did not exhibit phototoxic potential $(\mathrm{PIF}=0.368)$ for the dose

278 levels tested.

279

Genotoxicity was assayed starting from the highest concentration at which neither 280 necrosis nor cytotoxic or cytostatic effects was observed. When tested on the Chinese hamster 281 ovary $(\mathrm{CHO})-\mathrm{K} 1$ cell line, $\beta$-caryophyllene oxide did not produce any cytotoxic effects up to 282 a concentration of $5 \mu \mathrm{g} / \mathrm{mL}$. At concentrations of $0.5,1.0$ and $5.0 \mu \mathrm{g} / \mathrm{mL}, \beta$-caryophyllene oxide did not increase the MNC (micronucleated cells) frequency with respect to the control

284 (Table 6). No concentration of $\beta$-caryophyllene oxide induced an increase in MNC with or 285 without metabolic activation. These results indicated that the compound was not derived from 286 clastogenic/aneugenic activity and did not produce clastogenic/aneugenic metabolites (Table 287 $6)$. 

species having ecological distributions in many urban, peri-urban, or forest settings in close association with humans, and these species include Aedes albopictus and Anopheles dirus. Ae. albopictus, an important vector of dengue viruses in many urban and semi-forest communities, is a predominately day-biting mosquito, often found in and around human dwellings and preferentially feeds on humans (Chareonviriyaphap et al., 2003; Gomes et al., 2003), whereas An. dirus occurs in forest and forest-fringe habitats with a preference for night feeding and it is a major vector of malaria in several Asian countries (Suwonkerd et al., 2013; Tainchum et al., 2015). These two mosquito species have been found highly refractory to common control tools due to their mostly exophagic behavior and are regarded as excellent vectors even though they are present in low population densities. Therefore, the prevention and control of most vector-borne diseases remains dependent on various vector control strategies to decrease the transmission risk, which is a major challenge for outdoor-biting mosquitoes such as these 2 species.

Among the available vector control tools, chemical control remains the most used and effective in combatting mosquito vectors. A number of chemical compounds can protect humans from blood-feeding pests by one or more of three identified actions: contact irritancy, non-contact spatial repellency, or toxicity (Grieco et al., 2007). The first two properties are

307 potential outcome behavioral responses of mosquitoes after or before they make tarsi contact 308 with treated surfaces (Chareonviriyaphap et al., 1997; Roberts et al., 1997). Most studies have focused primarily on the insecticidal action of chemicals to control mosquitoes, whereas few investigations have played attention to the non-toxic properties, including irritancy and

311 repellency (Chareonviriyaphap et al., 2013; Chareonviriyaphap et al., 2004;

312 Chareonviriyaphap et al., 1997; Grieco et al., 2007). Moreover, much of the previous work 
has focused on potent synthetic compounds (Mongkalangoon et al., 2009; Thanispong et al., 2009). For years, the development of physiological resistance by mosquitoes to synthetic compounds has resulted in the reduced effectiveness of chemical-based prevention and control methods (Chareonviriyaphap et al., 2013). For this reason, the potential use of plant extracts or products derived from native plants as a source of essential oils for use as natural repellents is an attractive option to replace or supplement synthetic compounds for the control of vectors and the prevention of disease transmission (Desgrouas et al., 2016; Maia and Moore, 2011) as protection against mosquitoes and other arthropod pests in Thailand. These have included

Ocimum americanum L. (Hairy basil), Cymbopogon nardus (L.) Rendle (Citronella), Vetiveria zizanioides (L.) Nash (Vetiver), Citrus hystrix DC. (Kaffir lime), Cinnamomum verum J. Presl (Cinnamon leaf), Syzygium aromaticum (L.) Merr. \& L.M. Perry (Clove flower), and Zingiber officinale Roscoe (Ginger) (Boonyuan et al., 2014; Nararak et al., 2016; Nararak et al., 2017; Suwansirisilp et al., 2013). These essential oils have shown great promise as insect repellents and have been effective against several species of mosquitoes due to the presence of a variety of bioactive constituents that interfere with insect behavior and growth (Tisgratog et al., 2016; Tisgratog et al., 2018). The plant products have been effective as insect repellents or insecticidal agents and one of the potential repellent compounds is $\beta$-caryophyllene oxide (Nararak et al., 2019).

$\beta$-Caryophyllene oxide is a bicyclic sesquiterpene generated from the oxidation of $\beta$ caryophyllene and is found in a large number of plants worldwide (Fidyt et al., 2016). $\beta$ Caryophyllene oxide appears to be common among the essential oils that exhibit mosquito repellent ability (Jaenson et al., 2006; Trongtokit et al., 2005). Artabotrys hexapetalus (L.f.) Bhandari oil, obtained from leave parts, contains $\beta$-caryophyllene oxide as one of its major constituents and displays strong repellent activity against females of An. gambiae (Suleiman et 
al., 2014). Strong repellency against An. gambiae was also reported from a combination of linalool, $\beta$-caryophyllene oxide, $\gamma$-terpinene, and 1-methylpyrrole (45:39:8:8), and essential oil of Croton pseudopulchellus Pax (Odalo et al., 2005). Furthermore, (-)-caryophyllene oxide and (-)-limonene are the major chemical constituents found in essential oil extracted from the leaves of Perilla frutescens (L.) Britton, and provide good biting-deterrent activity (Tabanca et al., 2015).

$\beta$-Caryophyllene oxide has been approved as a food additive by the Food and Drug Administration (FDA) and the European Food Safety Authority (EFSA) (Fidyt et al., 2016). The two most common plant-associated repellent compounds are p-menthane-3,8-diol (derived from the Australian lemon-scented gum tree) and picaridin (a synthetic derivative of pepper); these have been tested for toxicity (U.S. EPA Biopesticide Registration Documents 011550 and 7505C) (EPA, 2019; Zhu et al., 2009). Phototoxic potential is assessed by comparing the differences in $\mathrm{IC}_{50}$ between negative control plates (not exposed to UVA) and test plates (exposed to UVA) (Roesler et al., 2010). The phototoxicity results obtained using the in vitro method are crucial because topical repellent formulations are also used during the day to protect against day-biting mosquitoes such as Aedes species, and this involves exposure to the sun and artificial light. The current study investigated the cytotoxicity and phototoxicity of $\beta$ caryophyllene oxide and showed that the compound was neither cytotoxic, nor phototoxic $(\mathrm{PIF}=0.38)$. The potential genotoxic effects from $\beta$-caryophyllene oxide have also been evaluated in mammalian cells. Likewise, the current study showed that $\beta$-caryophyllene oxide did not induce genotoxicity at the chromosomal level, as observed in the micronucleus assay. Di Sotto et al. (2013) reported that $\beta$-caryophyllene oxide was tested for mutagenic effects using the Ames test and micronucleus assay. Their results showed that the flavoring agent was

361 devoid of mutagenic effects, both at the gene level (frameshift or based-substitution mutations) and on chromosomes (clastogenicity and aneuploidogenicity), suggesting that $\beta$-caryophyllene 
oxide is also safe when used as a flavoring/fragrance ingredient. Then, this finding highlights the fact this component could be safe for human topical applications.

Nararak et al. $(2016,2017)$ reported that essential oils of citronella, vetiver, hairy basil, and kaffir lime had good irritant and repellent effects on mosquito vectors compared to DEET.

367 These studies suggested that plant-based substances have good potential efficacy to be alternative insect repellents. In the current study, mosquitoes displayed varying levels of behavioral escape responses to the compounds, indicating a clear dose response with concentration. The study showed that at higher concentrations $(0.5$ and $1.0 \%), \beta$-caryophyllene oxide had significantly greater repellent and irritant effects compared to DEET. Moreover, Ae. albopictus exhibited much stronger escape responses against $\beta$-caryophyllene oxide than $A n$. dirus for both contact and non-contact assays. Knockdown (37.83\%) was also found only in non-escape An. dirus mosquitoes in the contact trial at $1.0 \%$ concentration of $\beta$-caryophyllene oxide, whereas no knockdown and mortality at $24 \mathrm{~h}$ post exposure were observed for Ae. albopictus. The results in contact and non-contact trials indicated that escape responses of mosquitoes to the $\beta$-caryophyllene oxide were significantly greater than with DEET, similar to the previous study by Nararak et al. (2019) in which $\beta$-caryophyllene oxide was tested at concentrations of $0.1,0.25,0.5$ and $1.0 \%(\mathrm{v} / \mathrm{v})$ against Ae. aegypti and An. minimus and the results were compared to DEET at the same concentrations. The results showed that DEET displayed lower irritancy and repellent responses than $\beta$-caryophyllene oxide and An. minimus exhibited higher avoidance response rates (86-96\% escape) at $0.5 \%$ and $1.0 \%$ concentrations in contact and non-contact trials compared with Ae. aegypti (22-59\% escape). When comparing the results obtained with the four mosquito species tested with $\beta$-caryophyllene oxide, An. minimus presented the highest sensitivity to both types of escape responses (contact irritancy and noncontact-spatial repellency) at $0.5-1 \%(\mathrm{v} / \mathrm{v})$, followed by Ae. aegypti, Ae. albopictus, and An. dirus. Comparatively, DEET was less efficient than $\beta$-caryophyllene oxide 
at $0.5-1 \%(\mathrm{v} / \mathrm{v})$ for all 4 species as they presented lower escape responses in both trials, contact

389

390

391 former has high potential for further development as an alternative active ingredient in

392 mosquito repellent formulations, safe for humans and the environment. Such efficient repellent 393 products are in need. In a study done in Vietnam, forest-goers were in favor of using repellent

394 products to avoid mosquito-biting pressure (Ohrt et al., 2018). The use of repellent is a

395

396

397

398

399

400

401

402

403

404

405

406

407

408

409

410

411

412 complementary vector control method to standard ones such as bednets, long-lasting insecticidal nets (LLINs), indoor residual spraying (IRS), which has the advantage of repelling outdoor-biting mosquitoes, then reducing residual malaria transmission risk (Durnez and Coosemans, 2013). Then, appropriate formulations using $\beta$-caryophyllene oxide await development for its use as repellent for a safe protection against mosquito bites.

(1)
irritancy and noncontact-spatial repellency. Based on these results, $\beta$-caryophyllene oxide had stronger repellent and irritant effects than DEET at the same concentrations, suggesting the products to avoid mosquito-biting pressure (Ohrt et al, 2018). The use of repellent is a Coosemans, 2013). Then, appropriate formulations using $\beta$-caryophyllene oxide await development for its use as repellent for a safe protection against mosquito bites.

1

2


We acknowledge the financial support provided for this study by the Thailand Research 415 Fund through the International Research Network (Grant No. IRN58W0003416 IRN5803PHDW04). This study was also funded by the French Ministry of Foreign Affairs 417 (MEAE) through the Bio-Asie programme (BioVectrol project) and the PHC Siam 418 (BioVecThai project, Campus France No 33765NG). The first author (JN) was also granted 419 an Erasmus Mundus fellowship for 6 months.

420

421

\section{Conflict of interest}

The authors declare no conflict of interest.

423

424

Author Contributions

425

TC conceived and designed the experiments. JN, CS and CG performed the

426 experiments. JN, CS and CG analyzed the data. JN, CS and CG wrote the manuscript. SM, VML, EO and TC consulted and edited the manuscript. All authors read and approved the 428 manuscript.

429

430

431

432

433

434

435

436

437 
439 Abbott, W.S., 1987. A method of computing the effectiveness of an insecticide. 1925. J. Am. Mosq. Control Assoc. 3, 302-303.

441

442

443

444

445

446

447

448

449

450

451

452

453

454

455

456

457

458

459

460

Amichai, B., Lazarov, A., Halevy, S., 1994. Contact dermatitis from diethyltoluamide. Dermatitis 30, 188-189.

Antignac, E., Nohynek, G.J., Re, T., Clouzeau, J., Toutain, H., 2011. Safety of botanical ingredients in personal care products/cosmetics. Food Chem. Toxicol. 49, 324-341.

Baimai, V., Green, C., Andre, R., Harrison, B., Peyton, E., 1984. Cytogenetic studies of some species complexes of Anopheles in Thailand and Southeast Asia. Southeast Asian J. Trop. Med. Public Health 15, 536-546.

Benelli, G., Mehlhorn, H., 2018. Mosquito-borne Diseases: Implications for Public Health. Springer.

Boonyuan, W., Grieco, J.P., Bangs, M.J., Prabaripai, A., Tantakom, S., Chareonviriyaphap, T., 2014. Excito-repellency of essential oils against an Aedes aegypti (L.) field population in Thailand. J. Vector Ecol. 39, 112-122.

Briassoulis, G., Narlioglou, M., Hatzis, T., 2001. Toxic encephalopathy associated with use of DEET insect repellents: a case analysis of its toxicity in children. Hum. Exp. Toxicol. 20, 8-14.

Chareonviriyaphap, T., Akratanakul, P., Nettanomsak, S., Huntamai, S., 2003. Larval habitats and distribution patterns of Aedes aegypti (Linnaeus) and Aedes albopictus (Skuse), in Thailand. Southeast Asian J. Trop. Med. Public. Health 34, 529-535.

Chareonviriyaphap, T., Bangs, M.J., Ratanatham, S., 2000. Status of malaria in Thailand. Southeast Asian J. Trop. Med. Public Health 31, 225-237. 
461 Chareonviriyaphap, T., Bangs, M.J., Suwonkerd, W., Kongmee, M., Corbel, V., Ngoen-Klan, R., 2013. Review of insecticide resistance and behavioral avoidance of vectors of human diseases in Thailand. Parasites \& vectors 6, 280.

464 Chareonviriyaphap, T., Prabaripai, A., Bangs, M.J., 2004. Excito-repellency of deltamethrin on the malaria vectors, Anopheles minimus, Anopheles dirus, Anopheles swadiwongporni, and Anopheles maculatus, in Thailand. J. Am. Mosq. Control Assoc. 20, 45-54.

Chareonviriyaphap, T., Prabaripai, A., Sungvornyothrin, S., 2002. An improved excitorepellency test chamber for mosquito behavioral tests. J. Vector Ecol. 27, 250-252.

Chareonviriyaphap, T., Roberts, D., Andre, R.G., Harlan, H., Manguin, S., Bangs, M., 1997. Pesticide avoidance behavior in Anopheles albimanus, a malaria vector in the Americas. J. Am. Mosq. Control Assoc. 13, 171-183.

Chouin-Carneiro, T., Vega-Rua, A., Vazeille, M., Yebakima, A., Girod, R., Goindin, D., Dupont-Rouzeyrol, M., Lourenço-de-Oliveira, R., Failloux, A.-B., 2016. Differential susceptibilities of Aedes aegypti and Aedes albopictus from the Americas to Zika virus. PLoS Negl. Trop. Dis. 10, e0004543.

Debboun, M., Strickman, D., 2013. Insect repellents and associated personal protection for a reduction in human disease. Bull. Entomol. Res. 27, 1-9.

Desgrouas, C., Nararak, J., Tisgratog, R., Mahiou-Leddet, V., Bory, S., Ollivier, E., Manguin, S., Chareonviriyaphap, T., 2016. Comparative excito-repellency of three Cambodian plant-derived extracts against two mosquito vector species, Aedes aegypti and Anopheles minimus. J. Am. Mosq. Control Assoc. 32, 185-194. 
486

487

488

489

490

491

492

493

494

495

496

497

498

499

500

501

502

503

504

505

506

507

508

509

510

Durnez, L., Coosemans, M., 2013. Residual transmission of malaria: An Old issue for new approaches. In Anopheles mosquitoes-New insights into malaria vectors. Manguin S. Ed., IntechOpen, London, UK, 671-704.

EPA, 2019. Skin-Applied Repellent Ingredients. https://www.epa.gov/insect-repellents/skinapplied-repellent-ingredients.

Fidyt, K., Fiedorowicz, A., Strządała, L., Szumny, A., 2016. $\beta$-caryophyllene and $\beta$-caryophyllene oxide — natural compounds of anticancer and analgesic properties. Cancer Med. 5, 3007-3017.

Garneau, F.-X., Collin, G.J., Jean, F.-I., Gagnon, H., Arze, J.B.L., 2013. Essential oils from Bolivia. XII. Asteraceae: Ophryosporus piquerioides (DC) Benth. ex Baker. J. Essent. Oil Res. 25, 388-394.

Gertsch, J., Leonti, M., Raduner, S., Racz, I., Chen, J.-Z., Xie, X.-Q., Altmann, K.-H., Karsak, M., Zimmer, A., 2008. Beta-caryophyllene is a dietary cannabinoid. Proc. Natl. Acad. Sci. 105, 9099-9104.

Gomes, A., Silva, N., Marques, G., Brito, M., 2003. Host-feeding patterns of potential human disease vectors in the Paraíba Valley region, State of Säo Paulo, Brazil. J. Vector Ecol. 28, 74-78.

Grieco, J.P., Achee, N.L., Chareonviriyaphap, T., Suwonkerd, W., Chauhan, K., Sardelis, M.R., Roberts, D.R., 2007. A new classification system for the actions of IRS chemicals traditionally used for malaria control. PLos One. 2, e716.

Isman, M.B., 2002. Plant essential oils as green pesticides for pest and disease management. J. Am. Chem. Soc. 223, U668-U669.

Jaenson, T.G., Pålsson, K., Borg-Karlson, A.-K., 2006. Evaluation of extracts and oils of mosquito (Diptera: Culicidae) repellent plants from Sweden and Guinea-Bissau. J. Med. Entomol. 43, 113-119. 
Johnson, G.E., Jenkins, G.J., Thomas, A.D., Doak, S.H., 2010. Vinblastine and diethylstilboestrol tested in the in vitro mammalian cell micronucleus test (MNvit) at Swansea University UK in support of OECD draft Test Guideline 487. Mutat Res Genet Toxicol Environ Mutagen 702, 189-192.

Jun, N.J., Mosaddik, A., Moon, J.Y., Ki-Chang, J., Dong-Sun, L., Ahn, K.S., Cho, S.K., 2011. Cytotoxic Activity of [beta]-Caryophyllene Oxide Isolated from Jeju Guava (Psidium cattleianum Sabine) Leaf. Rec. Nat. Prod. 5, 242.

Liang, Q., Liang, Z.-S., Wang, J.-R., Xu, W.-H., 2009. Essential oil composition of Salvia miltiorrhiza flower. Food Chem. Toxicol. 113, 592-594.

Maia, M.F., Moore, S.J., 2011. Plant-based insect repellents: a review of their efficacy, development and testing. Malar. J. 10 (Suppl 1), S11.

Mantel, N., Haenszel, W., 1959. Statistical aspects of the analysis of data from retrospective studies of disease. J. Natl. Cancer Inst. 22, 719-748.

Mongkalangoon, P., Grieco, J.P., Achee, N.L., Suwonkerd, W., Chareonviriyaphap, T., 2009. Irritability and repellency of synthetic pyrethroids on an Aedes aegypti population from Thailand. J. Vector Ecol. 34, 217-224.

Nararak, J., Sathantriphop, S., Chauhan, K., Tantakom, S., Eiden, A.L., Chareonviriyaphap, T., 2016. Avoidance Behavior to Essential Oils by Anopheles minimus, a Malaria Vector in Thailand. J. Am. Mosq. Control Assoc. 32, 34-43.

Nararak, J., Sathantriphop, S., Kongmee, M., Bangs, M.J., Chareonviriyaphap, T., 2017. Excito-Repellency of Citrus hystrix DC Leaf and Peel Essential Oils Against Aedes aegypti and Anopheles minimus (Diptera: Culicidae), Vectors of Human Pathogens. J. Med. Entomol. 54, 178-186. 
534 Nararak, J., Sathantriphop, S., Kongmee, M., Mahiou-Leddet, V., Ollivier, E., Manguin, S., Chareonviriyaphap, T., 2019. Excito-repellent activity of $\beta$-caryophyllene oxide against Aedes aegypti and Anopheles minimus. Acta Trop. 197, XX-XX

Odalo, J.O., Omolo, M.O., Malebo, H., Angira, J., Njeru, P.M., Ndiege, I.O., Hassanali, A., 2005. Repellency of essential oils of some plants from the Kenyan coast against Anopheles gambiae. Acta Trop. 95, 210-218.

OECD, 2004. OECD Guidelines for the testing of chemical, No. 432: In vitro 3T3 NRU phototoxicity test. . Paris, France: Organization for economic cooperation and development. 4.

Ohrt, C., Ngo, T.D., Nguyen, T.Q., 2018. Preparing for the Next Global Threat: A Call for Targeted, Immediate Decisive Action in Southeast Asia to Prevent the Next Pandemic in Africa. In: Manquin, S. (Ed.), Towards Malaria Elimination: A Leap Forward. IntechOpen.

Patel, E., Gupta, A., Oswal, R., 2012. A review on: mosquito repellent methods. Int. J. Pharm. Chem. Biol. Sci. 2, 310-317.

Polanco-Hernández, G., Escalante-Erosa, F., García-Sosa, K., Chan-Bacab, M.J., SaguaFranco, H., González, J., Osorio-Rodríguez, L., Peña-Rodríguez, L.M., 2012. Metabolites from the leaf extract of Serjania yucatanensis with trypanocidal activity against Trypanosoma cruzi. Parasitol. Res. 111, 451-455.

Roberts, D.R., Chareonviriyaphap, T., Harlan, H.H., Hshieh, P., 1997. Methods of testing and analyzing excito-repellency responses of malaria vectors to insecticides. J. Am. Mosq. Control Assoc. 13, 13-17.

Roesler, R., Lorencini, M., Pastore, G., 2010. Brazilian cerrado antioxidant sources: cytotoxicity and phototoxicity in vitro. Food Sci. Technol. 30, 814-821. 
558 Sathantriphop, S., Ketavan, C., Prabaripai, A., Visetson, S., Bangs, M.J., Akratanakul, P., Chareonviriyaphap, T., 2006. Susceptibility and avoidance behavior by Culex quinquefasciatus Say to three classes of residual insecticides. J. Vector Ecol. 31, 266274.

Shell, E.R., 1997. Atlantic Monthly. Resurgence of a deadly diseases, 45-60.

Smith, C., 1956. The history of dengue in tropical Asia and its probable relationship to the mosquito Aedes aegypti. Am. J. Trop. Med. Hyg. 59, 243-251.

Suleiman, R.A., Mgani, Q.A., Nyandoro, S.S., 2014. Chemical compositions and mosquito repellency of essential oils from Artabotrys hexapetalus and Artabotrys rupestris. Int. J. Biol. Chem. Sci. 8, 2804-2812.

Suwansirisilp, K., Visetson, S., Prabaripai, A., Tanasinchayakul, S., Grieco, J.P., Bangs, M.J., Chareonviriyaphap, T., 2013. Behavioral responses of Aedes aegypti and Culex quinquefasciatus (Diptera: Culicidae) to four essential oils in Thailand. J. Pest Sci. 86, 309-320.

Suwonkerd, W., Ritthison, W., Ngo, C.T., Tainchum, K., Bangs, M.J., Chareonviriyaphap, T., 2013. Vector biology and malaria transmission in Southeast Asia, Anopheles mosquitoes-New insights into malaria vectors. IntechOpen.

Tabanca, N., Demirci, B., Ali, A., Ali, Z., Blythe, E.K., Khan, I.A., 2015. Essential oils of green and red Perilla frutescens as potential sources of compounds for mosquito management. Ind. Crop. Prod. 65, 36-44.

Tainchum, K., Kongmee, M., Manguin, S., Bangs, M.J., Chareonviriyaphap, T., 2015. Anopheles species diversity and distribution of the malaria vectors of Thailand. Trends Parasitol. 31, 109-119. 
581 Tananchai, C., Pattanakul, M., Nararak, J., Sinou, V., Manguin, S., Chareonviriyaphap, T.,

582

583

584

585

586

587

588

589

590

591

592

593

594

595

596

597

598

599

600

601

602

603

604 2019. Diversity and biting patterns of Anopheles species in a malaria endemic area, Umphang Valley, Tak Province, western Thailand. Acta Trop. 190, 183-192.

Tananchai, C., Tisgratog, R., Juntarajumnong, W., Grieco, J.P., Manguin, S., Prabaripai, A., Chareonviriyaphap, T., 2012. Species diversity and biting activity of Anopheles dirus and Anopheles baimaii (Diptera: Culicidae) in a malaria prone area of western Thailand. Parasites \& vectors 5, 211.

Telang, T., Awasthy, S., Oswal, V., 2003. Qualitative improvement of the essential oil of Chloroxylon swietenia (Roxb. corom). Indian Perfum. 47, 79-82.

Thanispong, K., Achee, N.L., Bangs, M.J., Grieco, J.P., Suwonkerd, W., Prabaripai, A., Chareonviriyaphap, T., 2009. Irritancy and repellency behavioral responses of three strains of Aedes aegypti exposed to DDT and alpha-cypermethrin. J. Med. Entomol. 46, 1407-1414.

Tisgratog, R., Sanguanpong, U., Grieco, J.P., Ngoen-Kluan, R., Chareonviriyaphap, T., 2016. Plants traditionally used as mosquito repellents and the implication for their use in vector control. Acta Trop. 157, 136-144.

Tisgratog, R., Sukkanon, C., Grieco, J.P., Sanguanpong, U., Chauhan, K.R., Coats, J.R., Chareonviriyaphap, T., 2018. Evaluation of the Constituents of Vetiver Oil Against Anopheles minimus (Diptera: Culicidae), a Malaria Vector in Thailand. J. Med. Entomol. 55, 193-199.

Trongtokit, Y., Rongsriyam, Y., Komalamisra, N., Apiwathnasorn, C., 2005. Comparative repellency of 38 essential oils against mosquito bites. Phytother. Res. 19, 303-309. WHO, 2018. World malaria report 2018. World Health Organization, Geneva, Switzerland, p. 165 . 
605 Wiwanitkit, V., 2011. Concurrent malaria and dengue infection: a brief summary and comment. Asian Pac. J. Trop. Biomed. 1, 326-327.

607 Yang, Y.C., Lee, H.S., Lee, S.H., Clark, J.M., Ahn, Y.J., 2005. Ovicidal and adulticidal 608 activities of Cinnamomum zeylanicum bark essential oil compounds and related compounds against Pediculus humanus capitis (Anoplura : Pediculicidae). Int. J. Parasitol. 35, 1595-1600.

611 Zhao, J., Zheng, X., Newman, R.A., Zhong, Y., Liu, Z., Nan, P., 2013. Chemical composition 612 and bioactivity of the essential oil of Artemisia anomala from China. J. Essen. Oil Res. 25, 520-525.

614 Zhu, J., Zeng, X.P., Berkebile, D., Du, H.J., Tong, Y., Qian, K., 2009. Efficacy and safety of 615 catnip (Nepeta cataria) as a novel filth fly repellent. Med. Vet. Entomol. 23, 209-216. 
619 non-contact chambers.

\begin{tabular}{|c|c|c|c|c|c|c|c|c|c|c|}
\hline \multirow[t]{3}{*}{ Compound } & \multirow[t]{3}{*}{ Test } & \multirow[t]{3}{*}{$\begin{array}{l}\text { Dose } \\
(\%)\end{array}$} & \multicolumn{4}{|c|}{ Aedes albopictus } & \multicolumn{4}{|c|}{ Anopheles dirus } \\
\hline & & & \multicolumn{2}{|c|}{ Treatment } & \multicolumn{2}{|c|}{ Control } & \multicolumn{2}{|c|}{ Treatment } & \multicolumn{2}{|c|}{ Control } \\
\hline & & & $\mathrm{N}$ & $\% \operatorname{Esp}^{(a)}$ & $\mathrm{N}$ & $\%$ Esp & $\mathrm{N}$ & $\% \operatorname{Esp}^{(a)}$ & $\mathrm{N}$ & $\%$ Esp \\
\hline \multirow[t]{8}{*}{$\begin{array}{l}\beta \text {-Caryophyllene } \\
\text { oxide }\end{array}$} & \multirow[t]{4}{*}{$\mathrm{C}$} & 0.1 & 60 & 3.51 & 60 & 5.00 & 60 & 0 & 60 & 8.33 \\
\hline & & 0.25 & 60 & 3.85 & 58 & 10.34 & 60 & 0 & 58 & 10.34 \\
\hline & & 0.5 & 60 & 46.43 & 61 & 8.20 & 62 & 26.32 & 61 & 6.56 \\
\hline & & 1.0 & 60 & 56.36 & 60 & 8.33 & 62 & 32.73 & 60 & 8.33 \\
\hline & \multirow[t]{4}{*}{$\mathrm{NC}$} & 0.1 & 60 & 1.75 & 60 & 5.00 & 60 & 3.51 & 60 & 5 \\
\hline & & 0.25 & 60 & 1.79 & 60 & 6.67 & 60 & 1.79 & 60 & 6.67 \\
\hline & & 0.5 & 60 & 31.03 & 61 & 4.92 & 60 & 31.03 & 61 & 4.92 \\
\hline & & 1.0 & 60 & 25.45 & 60 & 8.33 & 60 & 31.67 & 60 & 0 \\
\hline \multirow[t]{8}{*}{ DEET } & \multirow[t]{4}{*}{$\mathrm{C}$} & 0.1 & 60 & 0 & 60 & 8.33 & 60 & 3.57 & 60 & 5.08 \\
\hline & & 0.25 & 60 & 5.26 & 60 & 5 & 61 & 3.51 & 60 & 5.00 \\
\hline & & 0.5 & 60 & 38.98 & 60 & 1.67 & 60 & 16.98 & 59 & 11.67 \\
\hline & & 1.0 & 60 & 38.18 & 61 & 9.84 & 60 & 26.42 & 60 & 13.11 \\
\hline & \multirow[t]{4}{*}{$\mathrm{NC}$} & 0.1 & 60 & 6.7 & 60 & 0 & 60 & 3.57 & 60 & 5.08 \\
\hline & & 0.25 & 60 & 0 & 58 & 6.9 & 60 & 1.79 & 58 & 6.90 \\
\hline & & 0.5 & 60 & 8.93 & 60 & 6.7 & 59 & 8.93 & 60 & 6.67 \\
\hline & & 1.0 & 60 & 10 & 60 & 0 & 60 & 1.82 & 60 & 8.33 \\
\hline
\end{tabular}

620

$\mathrm{C}=$ contact; $\mathrm{NC}=$ non-contact; Esp $=$ escaped mosquitoes; $\mathrm{NE}=$ Non escape mosquitoes; ${ }^{\text {a }}$ Escape rates adjusted with paired controls using

621 Abbott's formula. 
622 Table 2. Comparisons of mosquito escape responses between contact and non-contact

623 chambers for Ae. albopictus and An. dirus exposed to $\beta$-caryophyllene oxide and DEET.

\begin{tabular}{llll}
\hline Compound & Dose $(\%)$ & \multicolumn{2}{l}{$P$-value } \\
\cline { 3 - 4 } & & Ae. albopictus & An. dirus \\
\hline B-Caryophyllene oxide & 0.1 & 0.7430 & 0.7274 \\
& 0.25 & 0.1510 & 0.7348 \\
& 0.5 & $0.0394^{*}$ & 0.7644 \\
& 1.0 & $0.0009^{*}$ & 0.5754 \\
\hline DEET & 0.1 & 0.9902 & 0.9898 \\
& 0.25 & 0.4858 & 0.7063 \\
& 0.5 & 0.3908 & 0.1368 \\
& 1.0 & $<0.0001^{*}$ & $0.0011^{*}$ \\
\hline
\end{tabular}

$624 *$ Indicates significant difference $(P<0.05)$ between contact and non-contact. 
625 Table 3. Comparisons of irritant and repellent actions between $\beta$-caryophyllene oxide and

626 DEET against Ae. albopictus and An. dirus in contact and non-contact chambers.

\begin{tabular}{llll}
\hline Compound & Dose $(\%)$ & $P$-value & \\
\cline { 3 - 4 } & & Contact & Non-contact \\
\hline Ae. albopictus & 0.1 & 0.7473 & 0.9828 \\
& 0.25 & 0.2850 & 0.7496 \\
& 0.5 & 0.1272 & 0.1994 \\
& 1.0 & $0.0142^{*}$ & $0.0030^{*}$ \\
\hline An. dirus & 0.1 & 0.9529 & 0.7945 \\
& 0.25 & 0.7748 & 0.7496 \\
& 0.5 & 0.5365 & $0.0193 *$ \\
& 1.0 & 0.7112 & $0.0030^{*}$ \\
\hline
\end{tabular}

$627 *$ Indicates significant difference $(P<0.05)$ between $\beta$-caryophyllene oxide and DEET. 
628 Table 4. Comparisons of escape responses between Ae. albopictus and An. dirus in contact

629 and non-contact chambers treated with $\beta$-caryophyllene oxide and DEET.

\begin{tabular}{llll}
\hline Compound & Dose $(\%)$ & $P$-value & \\
\cline { 3 - 4 } & & Contact & Non-contact \\
\hline B-Caryophyllene oxide & 0.1 & 0.7374 & 0.7334 \\
& 0.25 & 0.2681 & 1.0000 \\
& 0.5 & $0.0184^{*}$ & 1.0000 \\
& 1.0 & $0.0024^{*}$ & 1.0000 \\
\hline DEET & 0.1 & 0.9606 & 0.9606 \\
& 0.25 & 0.7495 & 1.0000 \\
& 0.5 & $0.0995^{*}$ & $0.0013 *$ \\
& 1.0 & 0.3584 & 1.0000 \\
\hline
\end{tabular}


631 Table 5. In vitro cytotoxic and phototoxic activity of $\beta$-caryophyllene oxide against mouse 632 normal fibroblast (BALB/c 3T3) cell lines.

\begin{tabular}{lllll}
\hline Compound & $\mathrm{IC}_{50}$ without irradiation & $\mathrm{IC}_{50}$ with irradiation & $\mathrm{PIF}$ & Phototoxicity \\
\hline $\begin{array}{l}\text { B-Caryophyllene } \\
\text { oxide }\end{array}$ & $13.23 \pm 1.37$ & $34.79 \pm 5.49$ & 0.38 & Non-phototoxic \\
$\begin{array}{l}\text { Chlorpromazine } \\
48.9 \pm 3.26\end{array}$ & $1.05 \pm 0.29$ & 54.71 & Phototoxic \\
\hline
\end{tabular}

633 Results are expressed as mean \pm SD 
634 Table 6. In vitro genotoxicity activity of $\beta$-caryophyllene oxide on CHO-K1 cells.

\begin{tabular}{|c|c|c|c|c|c|c|c|}
\hline \multirow{2}{*}{\multicolumn{2}{|c|}{$\begin{array}{l}\text { Compound } \\
\left(\% \text { or } \mu \mathrm{g} \cdot \mathrm{mL}^{-1}\right)\end{array}$}} & \multicolumn{3}{|c|}{ Assay performed without $\mathrm{S} 9 \mathrm{mix}$} & \multicolumn{3}{|c|}{ Assay performed with S9 mix } \\
\hline & & $\begin{array}{l}\text { Proliferative } \\
\text { Index (\%) }\end{array}$ & $\begin{array}{c}\text { MNC } \\
\text { (per 1,000) }\end{array}$ & $P$ & $\begin{array}{c}\text { Proliferative } \\
\text { Index }(\%)\end{array}$ & $\begin{array}{c}\text { MNC } \\
\text { (per 1,000) }\end{array}$ & $P$ \\
\hline \multicolumn{2}{|l|}{ Negative control } & 100 & $10.5 \pm 0.7$ & - & 100 & $10.5 \pm 2.1$ & - \\
\hline \multicolumn{2}{|l|}{ Positive control ${ }^{\S}$} & 98.2 & $31.5 \pm 2.1$ & $<0.001$ & 97.6 & $24.0 \pm 1.4$ & $<0.001$ \\
\hline \multicolumn{2}{|l|}{ Solvent control } & 98.6 & $9.5 \pm 0.7$ & $\mathrm{NS}^{\mathrm{a}}$ & 98.4 & $10.0 \pm 1.4$ & NS \\
\hline \multirow[t]{4}{*}{$\begin{array}{l}\beta \text {-caryophyllene } \\
\text { oxide }\end{array}$} & 0.5 & 99.7 & $10.5 \pm 2.1$ & NS & 98.8 & $9.5 \pm 0.7$ & NS \\
\hline & 1 & 98.4 & $11.0 \pm 1.4$ & NS & 97.4 & $13.0 \pm 2.8$ & NS \\
\hline & 5 & 65.1 & $9.5 \pm 2.1$ & NS & 73.2 & $11.0 \pm 1.4$ & NS \\
\hline & 10 & TOX & - & - & TOX & - & - \\
\hline
\end{tabular}

635 \$Positive controls: mitomycin $\mathrm{C}\left(0.05 \mu \mathrm{g} \cdot \mathrm{mL}^{-1}\right)$ without $\mathrm{S} 9 \mathrm{mix}$ and benzo-[a]-pyrene (5

$636 \mu \mathrm{g} \cdot \mathrm{mL}^{-1}$ ) with S9 mix; MNC: Micronucleated cells per 1,000; P: Probability of the comparison

637 between the negative control and the tested dose using the Chi-squared test; TOX: Toxic.

638 aNS: non-significant activity; Results are expressed as mean \pm SD 

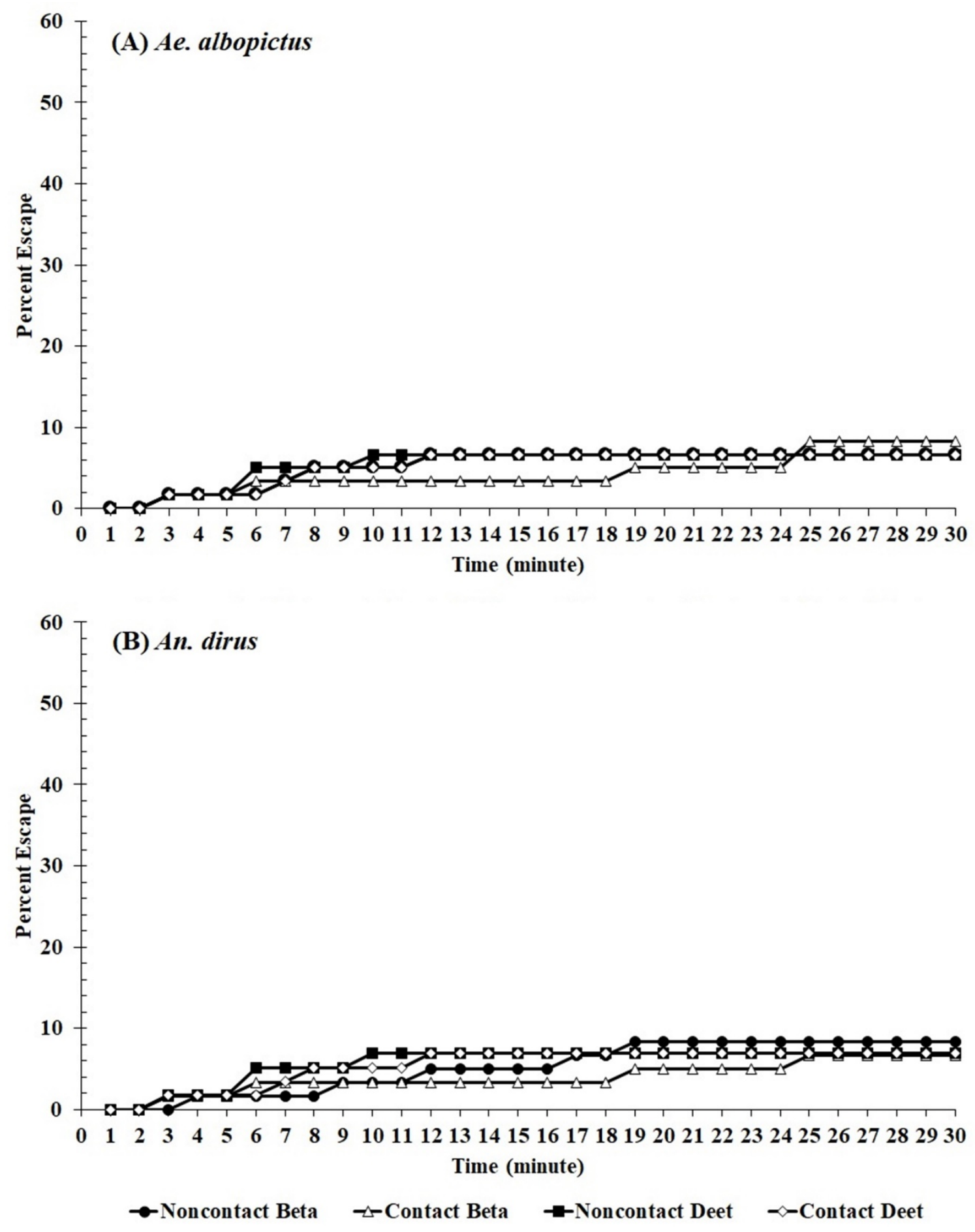

640 Fig. 1 Patterns of escape percentage from ER chambers for contact and noncontact assay 641 designs during $30 \mathrm{~min}$ exposure to $\beta$-caryophyllene oxide and DEET at $0.1 \%$ : (A) Ae. 642 albopictus, (B) An. dirus. 

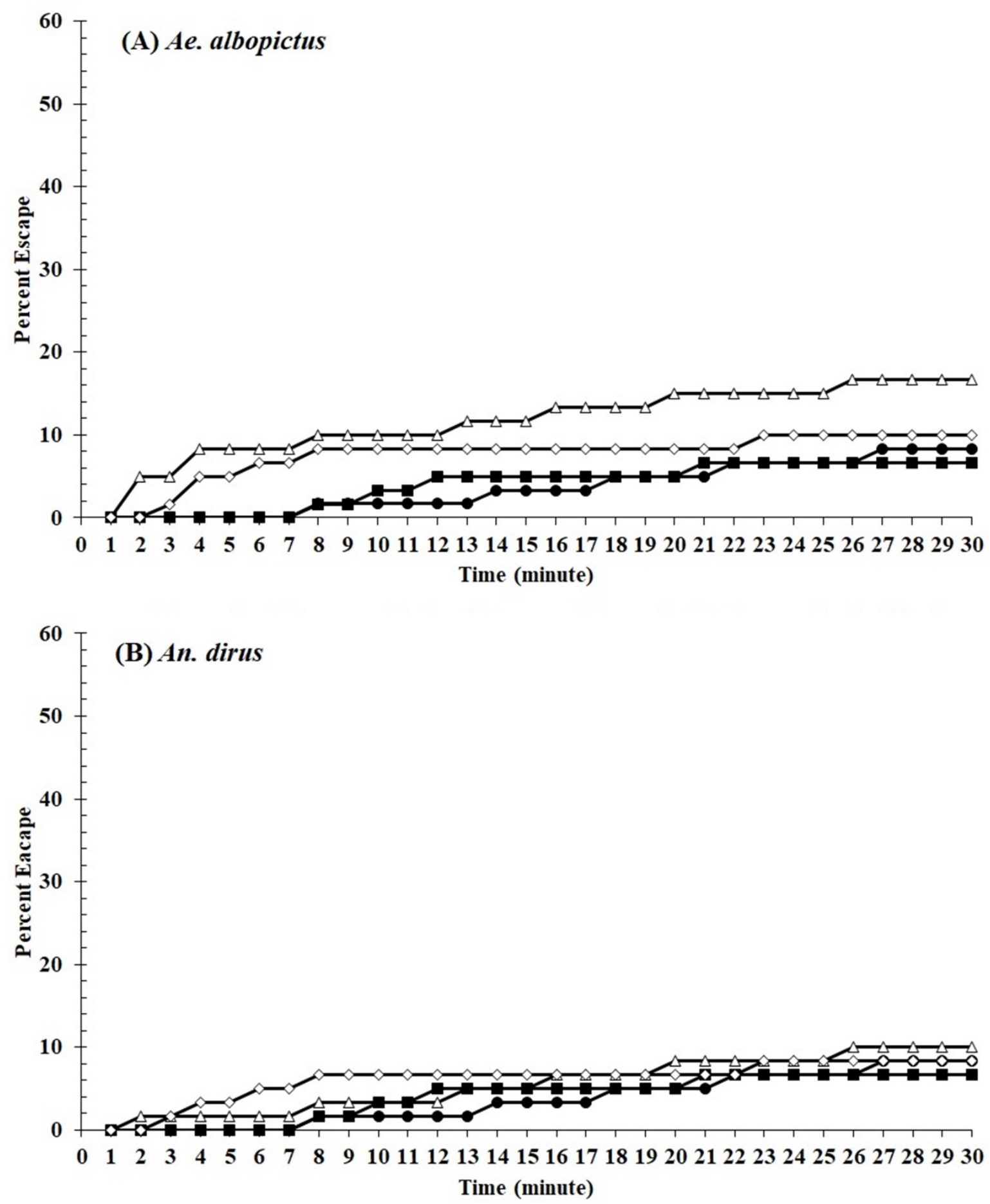

645 Fig. 2 Patterns of escape percentage from ER chambers for contact and noncontact assay 646 designs during $30 \mathrm{~min}$ exposure to $\beta$-caryophyllene oxide and DEET at $0.25 \%$ : (A) $A e$. 647 albopictus, (B) An. dirus 

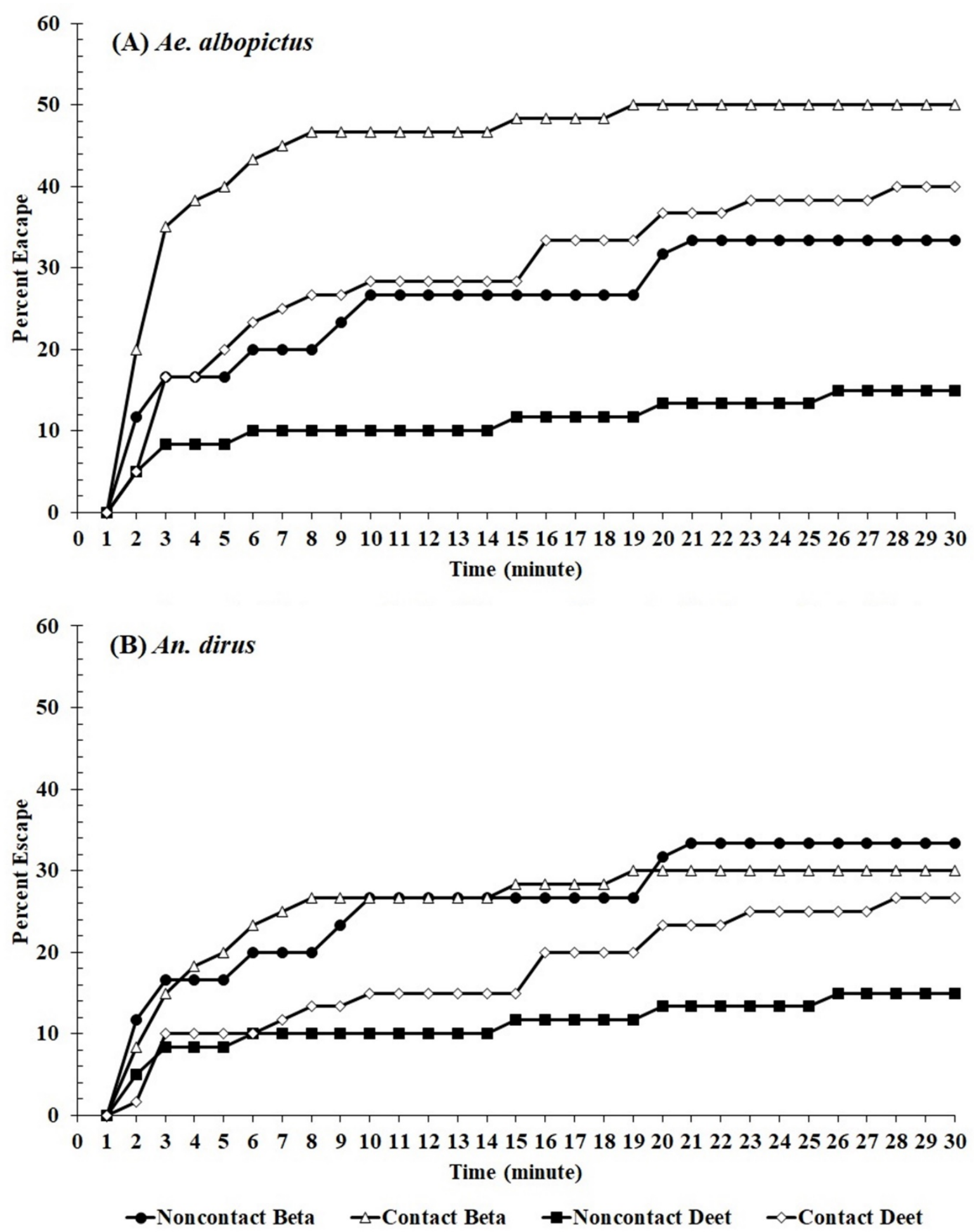

649 Fig. 3 Patterns of escape percentage from ER chambers under contact and noncontact assay 650 designs during 30 min exposure to $\beta$-caryophyllene oxide and DEET at $0.5 \%$ : (A) Ae. 651 albopictus, (B) An. dirus. 

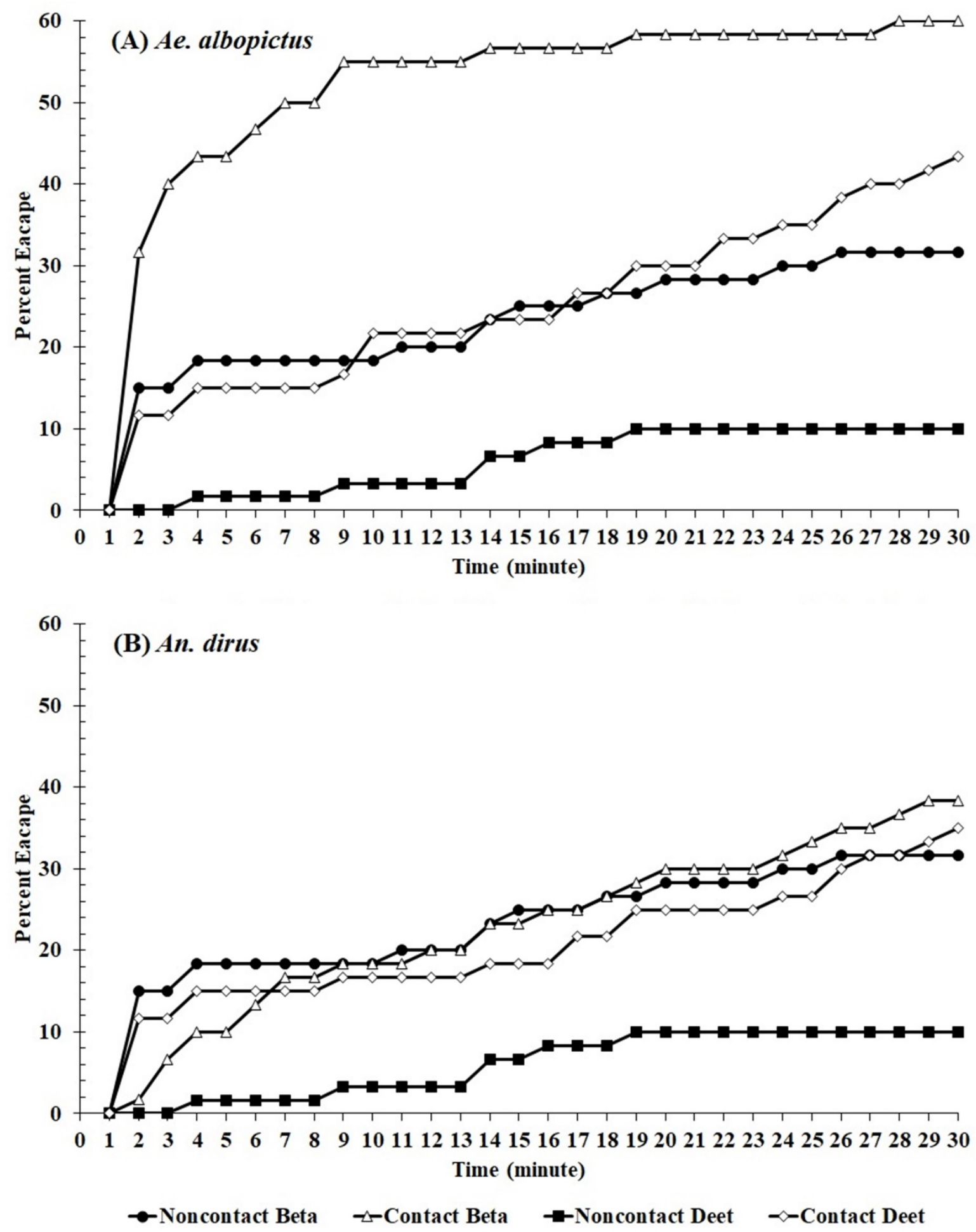

Fig. 4 Patterns of escape percentage from ER chambers under contact and noncontact assay

654 designs during 30 min exposure to $\beta$-caryophyllene oxide and DEET at 1\%: (A) Ae. albopictus, (B) An. dirus. 